\title{
Methylnaltrexone: the evidence for its use in the management of opioid-induced constipation
}

This article was published in the following Dove Press journal:

Core Evidence

10 December 2009

Number of times this article has been viewed

\author{
Peter Deibert ${ }^{1}$ \\ Carola Xander ${ }^{2}$ \\ Hubert E Blum ${ }^{3}$ \\ Gerhild Becker ${ }^{4}$ \\ 'Department of Rehabilitative \\ and Preventive Sports Medicine, \\ ${ }^{2}$ German Cochrane Center, \\ Department for Medical Statistics, \\ ${ }^{3}$ Department of Hepatology, \\ Gastroenterology, Endocrinology \\ and Infectious Diseases, ${ }^{4}$ Department \\ of Palliative Care, University Hospital, \\ Medical Clinic, Freiburg, Germany
}

Introduction: Constipation is a distressing side effect of opioid treatment, being so irksome in some cases that patients would rather suffer the pain than the side effect of opioid analgesics. Stool softeners or stimulating laxatives are often ineffective or even aggravate the situation. A new efficacious and safe drug is needed to limit the frequently observed side effects induced by effective opioid-based analgesic therapy and to improve the quality of life for patients, most of whom are impaired by a severe disease.

Aims: The purpose of this article is to assess current evidence supporting the use of the peripherally acting $\mu$-opioid receptor antagonist, methylnaltrexone, to restrict passage across the blood-brain barrier in patients with opioid-induced bowel dysfunction.

Evidence review: There are now convincing data from phase II and multicenter phase III randomized, double-blind, placebo-controlled trials that methylnaltrexone induces laxation in patients with long-term opioid use without affecting central analgesia or precipitation of opioid withdrawal. Onset of the effect is rapid and improvement is maintained for at least 3 months during the drug treatment. The action of methylnaltrexone is dose dependent. Weight-related dosing appeared to be effective. There were no severe side effects or signs of opioid withdrawal. Adverse events, most frequently abdominal cramping or nausea, were usually mild to moderate. Methylnaltrexone is contraindicated in patients with known or suspected mechanical intestinal stenosis. Patients receiving methylnaltrexone must be monitored.

Place in therapy: Methylnaltrexone applied subcutaneously every other day may be given to patients suffering from chronic constipation due to opioid therapy for whom laxatives do not provide adequate relief of their symptoms.

Keywords: constipation, methylnaltrexone, opioid-induced bowel dysfunction, opioid analgesics, chronic severe pain

Core evidence summary for methylnatrexon in the management of opioid-induced constipation

\begin{tabular}{|c|c|c|}
\hline Outcome measure & Evidence & Implications \\
\hline Reduction in hospitalization & No evidence & \\
\hline Improvement of quality of life & Weak evidence & $\begin{array}{l}\text { Patients more content with bowel } \\
\text { habits }\end{array}$ \\
\hline \multicolumn{3}{|l|}{ Patient-oriented evidence } \\
\hline $\begin{array}{l}\text { Methylnaltrexone accelerates opioid- } \\
\text { delayed gastric emptying }\end{array}$ & Clear & $\begin{array}{l}\text { Possible support in starting enteral } \\
\text { feeding in patients receiving opioids }\end{array}$ \\
\hline $\begin{array}{l}\text { Side effects of opioid antagonists are } \\
\text { mild to moderate with the approved } \\
\text { dosing }\end{array}$ & Clear & $\begin{array}{l}\text { Overdosing may lead to more } \\
\text { severe side effects without } \\
\text { increasing efficacy }\end{array}$ \\
\hline
\end{tabular}

Correspondence: Peter Deibert University Hospital, Department of Rehabilitative and Preventive Sports Medicine, Medical Clinic, Hugstetter Str. 55, 79106 Freiburg, Germany

Tel +49 76I $270746 \mid$

Fax +4976I 2707470

Email peter.deibert@uniklinik-freiburg.de 


\begin{tabular}{|c|c|c|}
\hline \multicolumn{3}{|l|}{ (Continued) } \\
\hline Outcome measure & Evidence & Implications \\
\hline $\begin{array}{l}\text { Risk of abdominal cramping is higher } \\
\text { with use of methylnaltrexone }\end{array}$ & Clear & $\begin{array}{l}\text { Abdominal cramping in mild to } \\
\text { moderate intensity is a possible } \\
\text { side effect }\end{array}$ \\
\hline Avoiding enemas & No evidence & \\
\hline \multicolumn{3}{|l|}{ Disease-oriented measurement } \\
\hline $\begin{array}{l}\text { Reversal of opioid-induced increased } \\
\text { transit time in healthy individuals }\end{array}$ & Clear & $\begin{array}{l}\text { Concomitant medication of methyl- } \\
\text { naltrexone and opioids during } \\
\text { anesthesia promising possibility, but } \\
\text { until now no evidence for general use }\end{array}$ \\
\hline $\begin{array}{l}\text { Reversal of opioid-induced increase } \\
\text { in orocecal transit time }\end{array}$ & Clear & $\begin{array}{l}\text { Half the patients treated will expe- } \\
\text { rience a laxation within a few hours } \\
\text { after the first application }\end{array}$ \\
\hline $\begin{array}{l}\text { Methylnaltrexone relieves } \\
\text { constipation in chronic opioid- } \\
\text { treated patients with advanced illness }\end{array}$ & Clear & $\begin{array}{l}\text { Useful in patients used to opioids, } \\
\text { who have a higher sensitivity to } \\
\text { methylnaltrexone }\end{array}$ \\
\hline Dose-dependent effect & Clear & $\begin{array}{l}\text { Dosing according to body-weight, } \\
\text { dose escalation not helpful }\end{array}$ \\
\hline $\begin{array}{l}\text { Efficacy without opioid withdrawal/ } \\
\text { analgesic reduction }\end{array}$ & Clear & $\begin{array}{l}\text { No increase in opioid dosing } \\
\text { necessary with methylnaltrexone } \\
\text { treatment }\end{array}$ \\
\hline Efficacy superior to laxatives & No evidence & $\begin{array}{l}\text { No direct comparative trials have } \\
\text { been performed }\end{array}$ \\
\hline Maintenance of clinical response & Weak & $\begin{array}{l}\text { Efficacy of methylnaltrexone is } \\
\text { unchanged at least during the } \\
\text { 3-month duration of therapy }\end{array}$ \\
\hline Reduced need for laxatives & Weak & $\begin{array}{l}\text { Additional laxatives may be } \\
\text { required and continued }\end{array}$ \\
\hline \multicolumn{3}{|l|}{ Economic evidence } \\
\hline $\begin{array}{l}\text { Cost effectiveness compared with } \\
\text { other laxatives }\end{array}$ & No evidence & $\begin{array}{l}\text { Long-term pharmacoeconomic } \\
\text { studies are needed }\end{array}$ \\
\hline
\end{tabular}

\section{Scope, aims, and objectives}

Cancer-related pain affects approximately 9 million people worldwide. As cancer progresses, an increasing fraction of patients require treatment with potent opioids, which may be administered via several routes. Opioid medication is frequently used for the pain suffered by palliative care patients with malignancies. However, morphine and related opioids are associated with various side effects: constipation, nausea, vomiting, pruritus, urinary retention, and so forth. ${ }^{1}$ Constipation is the most commonly occurring adverse effect of chronic opioid therapy in patients with advanced cancer. ${ }^{2}$ It is an almost inevitable consequence of opioid use in cancer and nonmalignant disease states. Schug and colleagues showed that in patients with cancer, constipation and vomiting were the most common adverse effects associated with opioid therapy. ${ }^{3}$ Unlike other adverse effects of opioid therapy, constipation is one of the side effects of opioids to which tolerance rarely develops. ${ }^{4}$ In most cases this problem is managed with stool softeners and laxatives. Presently, with the introduction of methylnaltrexone, it seems possible that a novel peripherally acting opioid antagonist can provide causal treatment for opioid-induced constipation (OIC), yet not interfere with the analgesic effect.

This review seeks to assess the scientific rationale for using methylnaltrexone to treat opioid-induced constipation and to discuss the current evidence for its therapeutic use.

\section{Methods}

We conducted a literature search on April 30, 2009 with OVID's http://www.ovid.com interface of the following databases: MEDLINE (including Medline in Process and other nonindexed citations) 1950 to April 30, 2009, the multifile database EBM Reviews (including Cochrane Database of Systematic Reviews, Cochrane Central Register of Controlled Trials, Database of Abstracts of Reviews 
Table I Evidence base included in the review

\begin{tabular}{lll}
\hline Category & \multicolumn{2}{l}{ Number of records } \\
\cline { 2 - 3 } & Full paper & Abstracts \\
\hline Initial search & 62 & 15 \\
$\quad$ Records excluded & 42 & 11 \\
Records included & 20 & 4 \\
Additional studies identified & 1 & 0 \\
Total records included & 21 & 4 \\
Level I clinical evidence & 4 & 0 \\
(systematic review, meta-analysis) & & \\
Level 2 clinical evidence (RCT) & 13 & 4 \\
Level 3 clinical evidence (trials & 4 & \\
without randomization, cohort) & & \\
Level 4 clinical evidence & & \\
(observational studies) & & \\
Economic evidence & 0 & \\
\hline
\end{tabular}

Notes: For definitions of levels evidence see inside back cover or Core Evidence website (http://dovepress.com/core-evidence-journal).

Abbreviation: RCT, randomized controlled trial.

of Effects, National Health Service Economic Evaluation Database) 1st quarter 2009, and BIOSIS Previews 1969 to 2009 Week 30. Additional searches were performed in CINAHL http://search.ebscohost.com 1982 to date, Science Citation Index Expanded http://www.isiknowledge.com 1945 to April 30, 2009, EMBASE (including EMBASE Alert) http://www.dimdi.de/static/de/db/dbinfo/em74.htm 1974 to April 30, 2009, and PubMed http://www.ncbi.nlm. nih.gov/entrez/query.fcgi? db=PubMed. No language restrictions were placed on the searches. The search terms included "methylnaltrexone", “constipation", "intestinal obstruction", "opioid-induced bowel disease" and the Cochrane Highly Sensitive Search Strategy for identifying randomized trials.

Our search strategy consisted of 3 steps. After identifying articles on opioid-induced constipation, we added the search results for peripherally acting opioid antagonists and limited the search to clinical trials in human beings. In addition we scanned the reference lists of the identified studies and performed internet searches with the terms listed above using Scirus http://www.scirus.com and Google Scholar http://scholar.google.de. Further trials were identified in specialized registers such as Current Controlled Trials http://www.controlled-trials.com, WHO Clinical Trials Registry Platform ICTRP http://www.who.int/trialsearch, National Institutes of Health Randomized Trials Records http://clinicaltrials.gov, and the Clinical Trials Database of the Association of the British Pharmaceutical Industry http://abpi.org.uk. After excluding duplicates and clearly irrelevant references, a total of 21 relevant publications were identified.

\section{Disease overview}

Most cancer-related pain can be managed effectively using orally administered analgesics. Current pharmacotherapy is based on the World Health Organization (WHO) concept of an analgesic ladder. ${ }^{5}$ The ladder suggests that clinicians should start with a non-opioid and, if pain is not controlled, progress to a weak opioid and then to a strong opioid. For patients with moderate to severe pain, oral morphine is conventionally the opioid of choice. ${ }^{6}$ The WHO analgesic ladder has been extensively validated and guidelines for the use of oral morphine have been presented. ${ }^{7}$ This framework of principles allows for flexibility in the choice of analgesics. It is one part of a comprehensive strategy for managing cancer pain. Some types of pain, such as neuropathic pain, may be less responsive to opioids than other types of pain, such as nociceptive, soft tissue pain. ${ }^{8}$ Morphine still is the drug of choice for managing moderate to severe cancer pain. No drug has been shown to have greater analgesic efficacy. Morphine is also the most cost effective analgesic. Consequently, in 2005 opioids were prescribed about 365 million times worldwide. ${ }^{9}$

Successful opioid-therapy requires that the benefits of analgesia clearly outweigh treatment-related adverse effects. This implies that a detailed understanding of adverse opioid effects and the strategies used to prevent and manage them are essential skills for all involved in cancer pain management. Constipation and nausea are the most incriminating side effects of opioid treatment. There is striking variability in individual sensitivity to the adverse effects from morphine and other opioid drugs. Genetic variability clearly affects the sensitivity to opioid analgesia, particularly with regard to codeine, dihydrocodeine and possibly, oxycodone. And it is reasonable to assume that genetic backgrounds play a similarly important role in the predisposition to adverse effects. ${ }^{10}$ These side effects should be kept in mind when patients are being treated with strong analgesics such as opioids and the treatment guidelines mentioned above should be followed.

Opioid-induced bowel dysfunction is increasingly recognized as a significant clinical problem and pathophysiological principles have been elucidated. Opioids inhibit propulsive gastrointestinal motility. ${ }^{11,12}$ Furthermore, there is increasing evidence that opiods have immunomodulatory effects, ${ }^{11,13,14}$ eg, the extended phase of postoperative ileus is caused by an enteric inflammatory response and recruitment of leucocytes to the muscularis of the bowel wall. 
Leucocytes produce the main inhibitory neurotransmitter of the gastrointestinal tract, nitric oxide, through the activity of the inducible isoform of nitric oxide synthase (iNOS). ${ }^{15}$ Opioids potentate iNOS induction and nitric oxide release from phagocytes; ${ }^{16}$ therefore, blockage of this opioidmediated response might be of specific use in reversing postoperative ileus. ${ }^{11}$ Opioid-induced bowel dysfunction can lead to various gastrointestinal complications ranging from mild discomfort to fecal impaction, pseudo-obstruction, and bowel perforation. ${ }^{17,18}$ A recent survey suggests that severe opioid bowel dysfunction reduces the value of pain relief by more than $30 \%$. In fact, many patients expressed a preference for uncontrolled pain over well-controlled pain with severe gastrointestinal adverse effects. ${ }^{17}$

Opioid-induced constipation can be exacerbated by metabolic alterations (diabetes, hypercalcemia, hypokalemia, uremia, hypothyreoidism), dehydratation, advanced age, reduced physical activity or immobility, low-fluid and/or low-fiber intake, difficulty reaching the bathroom, mechanical obstruction, neurological disorders, autonomic failure, drugs with anticholinergic action such as odansetron, diuretics, anticonvulsants, iron, vinca alkaloids, benzodiazepines and some antihypertensive drugs. ${ }^{10,19}$ The adverse effects of the other medications may be synergistic or cumulative to those associated with opioid medications and be due to an alteration in opioid absorption, metabolism or clearance of the opioid analgesics. ${ }^{20}$ Pharmacological interactions have to be considered. A change in medication may help in some cases. During the course of the disease, the physician has to distinguish between the adverse effects of morphine and the effects of co-morbidity or drug interactions.

\section{Current therapy options}

Gastrointestinal effects are the most common side effects of opioids. Opioid-induced bowel dysfunction affects the whole gut. It is often a greater problem for patients than pain. Nausea and emesis are common but usually resolve within days; prophylactic anti-emetics can help. Gastric stasis, satiety, flatulence, and constipation persist in most of the cases. A prokinetic drug, such as metoclopramide, may also be employed to reduce gastric stasis. ${ }^{2}$ Constipation is predictable and occurs in at least $90 \%$ of the patients. It is characterized by accumulation of gas and secretions and by retention of bowel content, leading to hard stools, incomplete evacuation, bloating, pain, nausea, and vomiting. Opioid-induced bowel dysfunction can occur immediately after the first dose and persist for the duration of therapy. It demonstrates a very weak dose relationship, so dose reduction is often ineffective.
Most guidelines on the management of opioid-related constipation recommend co-prescribing both softening and stimulating laxatives containing opioids. Stimulating laxatives should be used with caution in patients at risk of bowel obstruction. Furthermore, the long-term effectiveness and safety of such a regimen is unclear. There are no studies to indicate the superiority of one laxative over another in the management of opioid-induced constipation. Among the agents that have been suggested are docusate, senna, bisacodyl, phenolphthalein, and lactulose. Prospective data have demonstrated the efficacy of senna, ${ }^{21}$ sodium picosulfate, ${ }^{22}$ polyethylene glycol ${ }^{23}$ and oral naloxone. ${ }^{24}$ However, naloxone may reverse the analgesia. Titration to determine the best balance between the reduction of adverse effects and a satisfactory analgesia is challenging. In one small series, opioid rotation of morphine to methadone resulted in a reduction in constipation. ${ }^{25}$ Reduction of constipation was not reported in one observational study on changing the route of morphine administration. ${ }^{26}$ Recent crossover studies have demonstrated a reduced tendency to constipation among patients treated with transdermal fentanyl in place of oral morphine. ${ }^{27-31}$

\section{Unmet needs}

Bowel dysfunction is one of the most distressing adverse effects associated with opioid administration. ${ }^{18}$ Opioid-induced bowel dysfunction encompasses a range of different gastrointestinal symptoms, including straining, hard stools, incomplete evacuation, abdominal distension, bloating, increased gastroesophageal reflux, and constipation. ${ }^{32}$ Uncontrolled symptoms of opioid-induced bowel dysfunction can have a profound impact on the patient's quality of life. While constipation is well recognized as a common and unrelentingly adverse drug reaction to opioids, the importance of the impact of opioid-induced constipation on a patient's quality of life is generally not appreciated by healthcare professionals. Poor management of bowel dysfunction has a negative impact on a patient's quality of life.

Multiple approaches have been described to address the problem of opioid-induced constipation demonstrating the lack of a superior approach. ${ }^{33}$ Frequently, nonopioid pharmacological strategies are used for treating constipation: bulking agents and laxatives. The main effect of laxatives is limited to the emptying of the colon. Laxatives rarely provide adequate relief for all the complaints of the patient and frequently induce nausea, bloating, flatulence, distension, abdominal discomfort, and cramping abdominal pain. ${ }^{34-36}$ Furthermore, their efficacy in opioid-induced 
constipation has not been established. ${ }^{37,38}$ Centrally acting opioid antagonists often reverse the analgesic effects of opioid agonists in postoperative patients ${ }^{39-41}$ and produce withdrawal effects in patients on long-term opioid therapy, even in small doses. ${ }^{24,42}$ They are unsuitable for acute postoperative patients and chronic opioid users.

Therefore, there is an urgent need for more effective, better tolerated, and safe treatments that normalize bowel function in patients with impaired bowel function due to opioid therapy. The clinical challenge of selecting the best option is enhanced by the lack of definitive, evidence-based comparative data.

The search for opioid antagonists that act locally in the gut and do not reverse analgesia has involved the reformulation, or oral administration of existing antagonists, such as naloxone, and the development of new compounds. Peripheral opioid antagonists offer 2 distinct advantages for the prevention of opioid side effects: first, they do not reverse centrally mediated analgesia and secondly, a single drug may be used to prevent multiple adverse side effects. ${ }^{43}$ Therefore, these drugs represent a potential advance in medical therapy.

\section{Clinical evidence}

A number of phase I and II studies have established the pharmacodynamic, pharmacokinetic, therapeutic, and safety profile of methylnaltrexone. In healthy volunteers, both the parenteral and oral formulations, as well as single and repeated dosage regimens, were found to be effective in preventing the morphine-induced prolongation of gastric emptying and orocecal transit time without significantly attenuating morphine-induced analgesia. ${ }^{17,44-50}$

The first pilot, single-blind study in 4 patients with long-term methadone-induced constipation revealed immediate laxation and a dramatic reduction in orocecal transit time after intravenous (iv) application of methylnaltrexone ( 0.05 to $0.45 \mathrm{mg} / \mathrm{kg}$ iv).$^{47}$ However, 1 of the 2 subjects given $0.45 \mathrm{mg} / \mathrm{kg}$ twice daily had to stop the therapy due to abdominal cramping and was removed from the study. The other 2 patients received escalating doses starting with $0.05 \mathrm{mg} / \mathrm{kg}$ over 10 minutes for 4 days. This dose was increased after 10 minutes to $0.1 \mathrm{mg} / \mathrm{kg}$ over $15 \mathrm{~min}$, which caused an immediate laxation response in both patients. Doses of 0.05 to $0.15 \mathrm{mg} / \mathrm{kg}$ were equally effective for laxation and shortening of the orocecal transit time. Orocecal transit time was assessed by a lactulose breath test. The time between ingestion and the earliest detectable and sustained rise in pulmonary hydrogen excretion indicates that lactulose had reached the cecum and was recorded as the orocecal transit time. Stool frequency increased from 1 to 2 occurrences per week to 1.5 occurrences per day in the three patients evaluated and the orocecal transit time decreased from 150 minutes after placebo to 60 to 90 minutes following methylnaltrexone treatment.

In a larger randomized controlled trial, the same group confirmed these findings without any signs of opioid withdrawal. ${ }^{51}$ Twenty-two long-term methadone users were randomized to placebo or methylnaltrexone. The compound was administered intravenously as 9-minute infusions of increasing dosage from 0.015 to 0.05 and 0.1 to $0.2 \mathrm{mg} /$ $\mathrm{kg}$ body weight, with a 1-minute delay before the next dose, until the last dosage was given or the patient had a bowel movement. Ten out of the 11 patients treated with methylnaltrexone had immediate laxation responses during the day 1 afternoon session at a mean methylnaltrexone dose of $0.09 \mathrm{mg} / \mathrm{kg}$, and all 11 subjects had immediate laxation during the day 2 morning session ( $P<0.001$ vs placebo). No laxation response was observed in the 11 patients receiving placebo. During and immediately after each drug injection study, all subjects reported mild to moderate abdominal cramping, which they described as being similar to a defecation sensation, without discomfort. No opioid withdrawal symptoms were observed in any of these subjects during the study. No significant adverse effects were reported by the subjects. While baseline orocecal transit time did not differ significantly between the groups, the average change in transit times $( \pm \mathrm{SD})$ for subjects in the methylnaltrexone group $(n=11)$ was $-77.7 \pm 37.2$ minutes, significantly greater than that observed in the placebo group $(-1.4 \pm 12.0$ minutes; $P<0.001)$. Subjects in the treatment group were satisfied with their bowel movement activity. This trial demonstrates that individuals receiving long-term methadone treatment are much more sensitive to intravenous methylnaltrexone than healthy, opioid-naive subjects. In a phase I trial, healthy volunteers received up to $1.25 \mathrm{mg} / \mathrm{kg}$ methylnaltrexone. ${ }^{46}$ The dose-limiting adverse effect in this study was transient and self-limited, orthostatic hypotension.

The utility of subcutaneous (sc) methylnaltrexone to selectively counteract opiate-induced stasis in the gastrointestinal tract has been proven in phase II and phase III studies of patients with advanced illness requiring high doses of opiates for pain control. The efficacy and doseresponse relationship of methylnaltrexone in relieving opioid-induced constipation was first evaluated in a multicenter, randomized and parallel-group phase II trial involving 33 adult patients with advanced illness (defined as terminal 
or end-stage diseases such as metastatic cancer and AIDS) who were receiving chronic opioid therapy for pain on a daily basis. ${ }^{52}$ Patients were eligible for the study if they had a stable opioid drug dosage and no bowel movements for 2 days, reporting ongoing constipation even if they received conventional laxative therapy. The schedule of repeated methylnaltrexone treatment included a double-blind phase for 1 week, followed by an open-label phase for a maximum of 3 weeks. In the first week, study medication was administered on days 1,3 , and 5 whereas open label therapy could be administered as often as every other day. The initial dose range of $1 \mathrm{mg}, 5 \mathrm{mg}$, or $12.5 \mathrm{mg}$ was extended by adding a $20 \mathrm{mg}$ group during the study while still maintaining the double blind. Only one of 10 patients $(10 \%)$ who received the $1 \mathrm{mg}$ dose experienced laxation within 4 hours of dosing. The median time to laxation was $>48$ hours for the $1 \mathrm{mg}$ dose group, compared to 1.26 hours for all patients receiving $\geq 5 \mathrm{mg}(P=0.0003)$. There was no apparent increase in efficacy at doses above $5 \mathrm{mg}$. There were no changes in pain scores or evidence of opioid withdrawal.

Based on this study, 2 phase III trials of subcutaneous methylnaltrexone were conducted in patients suffering from opioid-induced constipation and end-stage diseases. ${ }^{53,54}$ In the first placebo-controlled, multicenter trial, methylnaltrexone $(0.15 \mathrm{mg} / \mathrm{kg})$ was given every other day for 2 weeks to 133 patients with advanced illness suffering from opioid-induced constipation. Eligible patients had a life expectancy of less than 6 months and opioid-induced constipation (less than 3 laxations in the prior week or no laxation in 48 hours); were receiving stable doses of laxatives and opioids; and were enrolled in hospice, nursing home, or palliative care programs. Patients were permitted to double the initial volume of the blinded study drug in week 2 if they had fewer than 3 rescue-free laxations (defined as laxation without the use of a rescue laxative, such as an enema or a suppository, after receipt of the study drug) in the first week. The double-blinded phase was followed by an open-label extension trial, during which patients received subcutaneous methylnaltrexone as needed up to every 24 hours for up to 3 months. The first open-label extension dose was administered more than 14 days after the first double-blind dose and more than 24 hours after the last double-blind dose. Subsequent doses could be increased to $0.30 \mathrm{mg} / \mathrm{kg}$ if no laxation occurred within 4 hours. The analysis of efficacy included 133 patients (62 in the methylnaltrexone group). Forty-eight percent of the patients given methylnaltrexone had a rescuefree laxation after receiving the first dose of the study drug compared with $15 \%$ in the placebo group $(P<0.001)$.
Significantly more patients in the methylnaltrexone group $(52 \%)$ had rescue-free laxation within 4 hours after 2 or more of the first 4 doses, as compared with the placebo group $(8 \% ; P<0.001)$. This high rate of response to therapy was maintained throughout the 2 -week double blind period and the 3-months extension period. The median time to laxation was approximately 30 minutes after administration of methylnaltrexone. Of the adverse events occurring in 5\% or more of patients in either study group, abdominal pain, flatulence, nausea, increased body temperature, and dizziness occurred more frequently in the methylnaltrexone group with an increase in incidence of 3 percentage points or more over that in the placebo group. Adverse events that occurred more frequently in the placebo group than in the methylnaltrexone group included falls and hypotension. The pattern of adverse events in patients who had a dose escalation to $0.3 \mathrm{mg} / \mathrm{kg}$ during the second week showed no meaningful differences between groups. The key goal of this randomized controlled study was to demonstrate that methylnaltrexone could safely and reliably produce laxation, without reversing analgesia or inducing opioid withdrawal symptoms, as it has been shown earlier in individuals using methadone. ${ }^{55}$

A second study enrolled 154 patients with advanced illness and opioid-induced constipation in a double-blind, randomized placebo-controlled trial, with an optional open-label phase (up to 4 months) in hospice and palliative care centers. ${ }^{54}$ Participants received a single subcutaneous injection of methylnaltrexone $(0.15 \mathrm{mg} / \mathrm{kg}$ or $0.3 \mathrm{mg} / \mathrm{kg}$ body weight) or a placebo. Laxation response within 4 hours was $62 \%$ and $58 \%$ for methylnaltrexone $0.15 \mathrm{mg} / \mathrm{kg}$ and $0.3 \mathrm{mg} / \mathrm{kg}$, respectively, compared with $14 \%$ for placebo $(P<0.0001)$. For all patients, the median time to rescue-free laxation was 1.10 hours in the methylnaltrexone $0.15 \mathrm{mg} / \mathrm{kg}$ group, 0.8 hours in the $0.3 \mathrm{mg} / \mathrm{kg}$ methylnaltrexone group, and $>24$ hours in the placebo group. Approximately half of the methylnaltrexone responders defecated within 30 minutes of dosing. Open-label phase response rates mirrored those for methylnaltrexone during the double-blind phase. There was no change in pain scores or evidence of central opioid withdrawal.

Karver et al describe 124 cancer patients receiving either placebo $(\mathrm{n}=42)$, methylnaltrexone $0.15 \mathrm{mg} / \mathrm{kg}(\mathrm{n}=37)$ or methylnaltrexone $0.3 \mathrm{mg} / \mathrm{kg}(\mathrm{n}=45) .{ }^{56}$ Patients had a life expectancy of 1 to 6 months, no laxation within 48 hours, and were maintained on stable opioids and baseline laxatives. The primary efficacy endpoints were laxation within 4 hours after a single dose of the study drug. 59.5\% of the patients receiving methylnaltrexone $0.15 \mathrm{mg} / \mathrm{kg}$ and $55.6 \%$ 
of those receiving $0.3 \mathrm{mg} / \mathrm{kg}$ had a rescue-free laxation within 4 hours compared to $16.7 \%$ in the placebo group $(P=0.0001)$. In another phase III study of this group, 78 cancer patients received either $0.15 \mathrm{mg} / \mathrm{kg}$ sc qod methylnaltrexone for 2 weeks (total of 7 doses) or placebo. ${ }^{56}$ The primary efficacy endpoints were laxation within 4 hours after at least 2 of the first 4 doses of the study drug. A majority of the methylnaltrexone-treated cancer patients had a laxation within the first 4 hours after study-drug administration (51.4\% of methylnaltrexone treated patients compared to $14.6 \%$ in the placebo group, $P=0.0007$ ). At least 2 laxations were observed in $59.5 \%$ of the treated patients during the 4 hour period after the first 4 doses compared to $7.3 \%$ of the placebo group $(P<0.0001) .{ }^{56}$ In both studies, no loss of pain control or opioid withdrawal was observed.

\section{Other indications}

A further phase II, double-blind, randomized placebo-controlled trial evaluated methylnaltrexone $(0.3 \mathrm{mg} / \mathrm{kg}$ iv $)$, administered every 6 hours for a maximum of 7 days, in 65 patients after segmental colectomy for the treatment of postoperative bowel dysfunction. Postoperative analgesics included morphine and fentanyl. The time to first bowel movement was significantly decreased in the methylnaltrexone group (98 \pm 5.7 hours) compared to the placebo group $(118 \pm 10.3$ hours; $P=0.038)$, as was the time to discharge eligibility $(116.1 \pm 6.9$ versus $148.7 \pm 17.2$ hours; $P=0.049$ ). The time to toleration of full liquids, solid foods, and actual discharge were reduced, which favors treatment, but these effects did not reach statistical significance. ${ }^{57}$ Further randomized controlled studies are currently under way to clarify the impact of methylnaltrexone.

One hundred and twenty female patients undergoing laparoscopic surgery under balanced anesthesia were included in a phase II study ${ }^{58}$ Participants received either methylnaltrexone (20 mg iv) or a placebo at the end of surgery. The incidence of nausea was $27 \%$ and $20 \%$ for placebo and methylnaltrexone, respectively, and $18 \%$ and $10 \%$ of patients experienced emesis, respectively. These findings were not significant and suggested that methylnaltrexone did not prevent or reduce the incidence of nausea and emesis.

In a double-blind, randomized crossover trial, the effect of methylnaltrexone $(0.3 \mathrm{mg} / \mathrm{kg}$ iv $)$ on opioid (remifentanil)-induced bladder dysfunction was evaluated. ${ }^{59}$ Thirteen healthy male volunteers received an intravenous) infusion of remifentanil, $0.15 \mu \mathrm{g} / \mathrm{kg} /$ minute, followed by a single intravenous dose of the study medication,meth ylnaltrexone $0.3 \mathrm{mg} / \mathrm{kg}$, naloxone $0.01 \mathrm{mg} / \mathrm{kg}$, or saline).
Urodynamics were measured with indwelling bladder and rectal catheters, and pupil size was assessed with infrared pupillometry. Remifentanil decreased detrusor pressure in $21 / 25$ sessions and caused complete urinary retention in $18 / 25$. Voiding was possible in $7 / 7,5 / 12$, and $0 / 6$ sessions after naloxone, methylnaltrexone, and saline, respectively $(P=0.0013)$. Remifentanil caused marked miosis that was reversed by naloxone, but not methylnaltrexone or placebo $(P<0.0001)$. Pupil data confirm that methylnaltrexone did not reverse the central opioid effects. Reversal of urinary retention by methylnaltrexone indicates that peripheral mechanisms may play a role in opioid-induced bladder dysfunction.

Opioids decrease the tone of gastric smooth muscles and increase the tone of sphincters. Gastric emptying is a function of both these effects. Two studies showed that methylnaltrexone attenuates the morphine-induced delay of gastric emptying, suggesting that gastric emptying is a peripheral effect of opioids. ${ }^{45,60}$ Eleven healthy volunteers were given placebo, morphine $(0.09 \mathrm{mg} / \mathrm{kg})$, or a combination of morphine and methylnaltrexone, and the rate of gastric emptying was measured by tests for bioimpedance and acetaminophen absorption. ${ }^{45}$ The time for $50 \%$ emptying was $5.5,21.0$, and 7.4 minutes after administration of placebo, morphine, and morphine/methylnaltrexone, respectively. Morphine delayed acetaminophen transfer from the stomach to the proximal jejunum and decreased the acetaminophen peak plasma concentration. ${ }^{45,60}$ These effects were also prevented by methylnaltrexone. ${ }^{45,60}$

\section{Tolerability and safety}

In a phase I study of 14 healthy volunteers, no adverse effects of clinical importance were observed after oral administration of up to $19.2 \mathrm{mg} / \mathrm{kg}$ body weight methylnaltrexone. ${ }^{44}$ It was found that oral methylnaltrexone decreased the subjective ratings of skin itching and flushing caused by intravenous morphine. ${ }^{44,61}$ A low plasma bioavailability of oral methylnaltrexone has been reported in these studies. This systemic bioavailability can be compared to that with naloxone, a commonly used opioid antagonist, in which systemic bioavailability after oral ingestion is only approximately $2 \%$ because of the high hepatic first-pass metabolism. ${ }^{62}$

As a charged compound, methylnaltrexone's absorption in the gut may be limited, contributing in part to the low bioavailability. Less than $1 \%$ of the parent compound was excreted in the urine up to 6 hours after oral dosing, further suggesting a restricted absorption by the gut. ${ }^{44}$ In their study of oral methylnaltrexone with maximum dosing of $3.0 \mathrm{mg} / \mathrm{kg}$ 
for patients receiving long-term methadone therapy, Yuan and co-workers, found no significant side effects. ${ }^{55}$ Most patients reported very mild abdominal cramping after oral methylnaltrexone, which they described as similar to a defecation sensation without discomfort. However, in this study 8 of 12 enrolled participants had undetectable plasma methylnaltrexone levels.

Twelve healthy volunteers were given methylnaltrexone intravenously at doses of $0.45 \mathrm{mg} / \mathrm{kg}$, placebo or morphine $(0.05 \mathrm{mg} / \mathrm{kg}) .{ }^{17} \mathrm{No}$ adverse effects of clinical importance were observed in this study. In another trial, methylnaltrexone was administered intravenously, up to a dosage of $0.365 \mathrm{mg} / \mathrm{kg}$, to patients chronically using methadone. ${ }^{51}$ No significant adverse effects were mentioned.

In another study methylnaltrexone was applied to healthy male volunteers in 6 ascending doses with a placebo randomly inserted into the sequence. Each participant was observed for subjective and hemodynamic changes. The dose-limiting effect of intravenous methylnaltrexone was orthostatic hypotension at $0.64 \mathrm{mg} / \mathrm{kg}(\mathrm{N}=3)$ or $1.25 \mathrm{mg} / \mathrm{kg}$ $(\mathrm{N}=5)$, which was transient and self-limiting. Plasma levels of methylnaltrexone in excess of $1.400 \mathrm{ng} / \mathrm{mL}$ were observed to be associated with orthostatic hypotension. There were no significant, subjective changes, no release in histamine, and no changes at physical examination or in laboratory results during the course of this study. ${ }^{46}$ Pharmacokinetic analyses revealed an elimination half life of $117.5 \pm 53.2$ minutes and a clearance of $38.8 \pm 17.4 \mathrm{~L} /$ hour, with a methylnaltrexone dose of $0.64 \mathrm{mg} / \mathrm{kg}$ iv.

In most of the studies concerning patients with advanced illness, subcutaneous application has been used, doses ranging from $0.1 \mathrm{mg} / \mathrm{kg}$ to $0.3 \mathrm{mg} / \mathrm{kg}$. ${ }^{49,53,54}$ Evidence of withdrawal mediated by central nervous system opioid receptors or changes in pain scores were not observed. Abdominal pain (in up to $45 \%$ of patients) and flatulence were the most common adverse effects, being mild to moderate and dose dependent. Slatkin et al describe severe adverse events occurring during the open-label phase of their study. ${ }^{54}$ One patient had flushing, another had delirium possibly related to methylnaltrexone, and a third patient had severe diarrhea with subsequent dehydration and cardiovascular collapse and death.

Although methylnaltrexone was significantly more effective than the placebo (at least 3 times as effective), it is somewhat disappointing that rescue-free laxation will happen only in about half of the patients. There may be several reasons for this failure. First, the predominant causes of constipation among the patients who did not respond to methylnaltrexone therapy could have been caused by other drugs or disease processes unrelated to actions mediated by opioid receptors. Second, central actions of opioids contribute as well, having not been modified by a peripherally acting antagonist.

The half-life of subcutaneously administered methylnaltrexone is about 8 hours. Methylnaltrexone is primarily eliminated as an unchanged drug ( $85 \%$ of the administered dose). Approximately one-half of the dose is excreted in urine and less in feces. ${ }^{17,46,50,55}$ Methylnaltrexone is also metabolized into 5 distinct metabolites. N-demethylation to naltrexone is not significant.

\section{Drug interactions}

Methylnaltrexone is a weak inhibitor of CYP450 2D6 in vitro; however, in vivo, it has not affected the metabolism of the CYP2D6 substrate dextromethorphan. In vitro, it does not inhibit CYP1A2, CYP2A6, CYP2C9, CYP2C19, or CYP3A4. The potential for drug interactions with agents that are actively secreted by the kidney has not been studied in humans. ${ }^{63}$

\section{Economic evidence for the use of methylnaltrexone}

There is a clinical need for effective treatment of opiateinduced constipation, because constipation is not only a frequent but also a distressing symptom. ${ }^{1}$ Any measure that improves the tolerability of opioid analgesics represents progress in the treatment of pain. ${ }^{64}$ The use of methylnaltrexone concurrent with opioid therapy in patients with chronic malignancy-associated pain may reduce the burden of hospice, nursing home and palliative care programs to provide patient care. However, there are no published data on the assessment of resource utilization with methylnaltrexone for opioid-induced bowel dysfunction in patients with advanced illness.

\section{Patient group/population}

Methylnaltrexone is approved by the US Food and Drug Administration (FDA) to help restore bowel function in patients with late-stage, advanced illness who are receiving continuous opioids; that is, methylnaltrexone is a treatment for opioid-induced bowel dysfunction, when response to laxatives has not been sufficient.

In this context it is worth noting, that methylnaltrexone is also able to ameliorate opioid-induced urinary retention, ${ }^{59}$ itching and nausea. There is some weak evidence that methylnaltrexone may relieve postoperative ileus. 
Methylnaltrexone does not reverse opioid-mediated ventilatory depression, a centrally mediated opioid effect. ${ }^{65}$ Therefore methylnaltrexone cannot be used, like naloxone, to treat patients with an opioid overdose.

\section{Dosage, administration, and formulations}

The drug has been formulated as a solution for intravenous or subcutaneous administration and as capsules/tablets for oral administration. Both the parenteral and oral formulations, as well as single and repeated dosage regimens, have been found to be efficacious in preventing the morphine-induced prolongation of gastric emptying and orocecal transit time without significantly attenuating morphine-induced analgesia. ${ }^{66-68}$ The drug has been approved for subcutaneous application which ensures ease of use in both the hospice and home setting, in contrast to intravenous drug administration. Methylnaltrexone was approved by the FDA in April 2008 to help restore bowel function in patients with late-stage, advanced illness who are continually receiving opioids, when response to laxative therapy has not been sufficient. It is also approved by Health Canada and the European Medicine Agency. The recommended dosage is $8 \mathrm{mg}$ every other day for a body weight between 38 to $62 \mathrm{~kg}$ and $12 \mathrm{mg}$ every other day for a body weight of 63 to $114 \mathrm{~kg}$. For a body weight beyond these outlines, the dose in $\mathrm{mg}$ should be calculated as $0.15 \mathrm{mg} \times$ body weight in kilograms. It should not be dispensed more frequently than 1 dose in a 24 -hour period. ${ }^{63}$ It should be administered as a subcutaneous injection in the upper arm, abdomen, or thigh. ${ }^{63}$ Methylnaltrexone is contraindicated in patients with known or suspected mechanical intestinal stenosis or acute abdominal distress.

Further clinical studies are needed to define, long term, the optimal dosage, optimal dosing regimen, and the optimal efficacy/safety profile of methylnaltrexone. The therapeutic value of methylnaltrexone cannot be fully appreciated before its long-term efficacy and safety record have been disclosed. Since methylnaltrexone is likely to be used in multimorbid patients, its interaction with other drugs and the necessity of dose adjustment in patients with renal insufficiency or failure also need to be determined. ${ }^{68}$ In patients with severe renal function impairment (creatinine-clearance less than $30 \mathrm{~mL} /$ minute), the dose should be reduced by one-half. ${ }^{63}$ There are no data available for its use in young patients.

Methylnaltrexone for subcutaneous injection is available as a $12 \mathrm{mg}$ per $0.6 \mathrm{~mL}$ solution in singleuse vials. Product excipients are sodium chloride $3.9 \mathrm{mg}$, edentate calcium disodium $0.24 \mathrm{mg}$, glycine hydrochloride $0.18 \mathrm{mg}$, and hydrochloric acid and/or sodium hydroxide to adjust $\mathrm{pH}$. The product will be available in prefilled syringes at a later date. Storage is recommended at room temperature $\left(20^{\circ}\right.$ to $25^{\circ} \mathrm{C}$; $68^{\circ}$ to $72^{\circ} \mathrm{F}$ ); excursions are permitted between $15^{\circ}$ and $30^{\circ} \mathrm{C}$ $\left(59^{\circ}\right.$ and $\left.86^{\circ} \mathrm{F}\right)$. The compound should be protected from light. Once drawn into a syringe, if immediate administration is not possible, the product should be stored at room temperature and administered within 24 hours; protection from light is not necessary during this period. ${ }^{63}$

\section{Place in therapy}

Opioid analgesics are the mainstay therapy for moderateto-severe pain in patients with serious illness. Side effects, such as constipation, nausea, and vomiting, may be disabling to such a degree that opioid treatment needs to be reduced or even abandoned. The traditional approach to ameliorate opioid-induced constipation is laxative co-medication which, however, can be both ineffective and distasteful to the patient. The majority of the currently available treatments are relatively ineffective in this context and have not been tested in well-controlled modern trials. A major limitation of chronic treatment with laxatives, however, is that although they increase stool frequency, they do not relieve all the constipation-associated symptoms such as bloating, abdominal discomfort, and pain, resulting in poor compliance. They also may induce troublesome adverse events including flatulence, bloating, and abdominal cramping pain. ${ }^{69}$

The spectrum of adverse opioid actions on the gut reflects the ability of these analgesic drugs to directly interact with the pathways of the enteric nervous system which regulates gastrointestinal motility and secretion. In addition, there is evidence that opioid receptors in the brain can cause gastrointestinal effects. However, experimental and clinical studies with opioid-receptor antagonists that are unable to enter the brain have shown that the adverse gastrointestinal effect profile of opioid receptor antagonists is essentially of a peripheral origin. Methylnaltrexone is a member of a new class of peripherally acting $\mu$-receptor opioid antagonist drugs. The addition of a methyl group to the naltrexone molecule makes methylnaltrexone positively charged and hydrophilic, thereby preventing transport across the bloodbrain barrier. Hence it neither reverses central nervous system opioid analgesia nor causes withdrawal in opioid-tolerant patients. Methylnaltrexone, administered subcutaneously, has recently been approved by the FDA, as well as by Health Canada and the European Medicines Agency. In the United States, it is indicated for the treatment of opioid-induced constipation in patients with advanced illness (eg, cancer, 
AIDS) who are receiving palliative care, when response to laxative therapy has not been sufficient.

Methylnaltrexone is well tolerated and remained effective in randomized controlled trials of up to 16 weeks. The heterogeneity of dosage regimens and routes of administration make it difficult to suggest an optimal approach. The effects on stool frequency, constipation-associated symptoms as well as adverse effects are dose related. There was no further improvement in efficacy above a dose of $0.3 \mathrm{mg} / \mathrm{kg}$. The percentages of responders to 0.15 and $0.3 \mathrm{mg} / \mathrm{kg}$ appear to be similar, the latter being combined with a higher rate of adverse events. A single daily dose appears appropriate, being followed by subsequent doses every other day. Only if there is no response to therapy would daily application be suggested. The response rate in patients with advanced illness is supposed to be between $50 \%$ and $60 \%,{ }^{53,54}$ half of the patients responding within 30 minutes after drug administration.

At therapeutic doses $(0.3$ to $0.45 \mathrm{mg} / \mathrm{kg}$ iv and up to $19.2 \mathrm{mg} / \mathrm{kg}$ orally) methylnaltrexone is well tolerated, an outcome that is also true when methylnaltrexone is repeatedly administered at $0.3 \mathrm{mg} / \mathrm{kg}$ iv every 6 hours. The incidence of adverse reaction with the opioid antagonist is similar to placebo and generally reported as mild to moderate. ${ }^{70}$ The main adverse reactions being reported relate to the vascular or the gastrointestinal system. Transient orthostatic hypotension can occur at supra-therapeutic doses. ${ }^{64,66-68}$ This reaction may cause the facial flushing and mild light-headedness, symptoms that have occasionally been reported. The other type of adverse effect comprises gut-related reactions, such as abdominal cramping, soft stools, and diarrhea. . $^{50,64,66-68}$

The preliminary data on improvement of gastric emptying in opioid-receiving patients indicate that methylnaltrexone could have further advantages. ${ }^{45}$ By decreasing the volume of gastric contents, methylnaltrexone may decrease the risk of regurgitation and pulmonary aspiration. This effect may be of particular importance in patients undergoing general anesthesia. Because the esophageal sphincter is relaxed and the patients are in a supine position, protective airway reflexes are absent. Furthermore, methylnaltrexone may increase that drug's rate of absorption and peak concentration by increasing the rate at which an orally administered drug passes into the proximal small bowel and by decreasing gastric residuals. In the same way methylnaltrexone may support the effort for enteral readings to be administered to patients who are taking large doses of opioids - an effect that may be of great importance for patients in the intensive care unit who are taking large doses of opioids. No controlled studies of the effects of methylnaltrexone on enteral nutrition have been conducted. However, one case report describes the successful use of methylnaltrexone to initiate feedings in a patient with a $30 \%$ burn. $^{71}$ Peripheral opioid antagonists also may be useful for treating and avoiding nausea and vomiting, other well-known adverse effects of opioids that may have both peripheral and central components. In one small study, methylnaltrexone markedly attenuated the nausea associated with parenteral morphine administration..$^{49}$ In another small study, patients who received methylnaltrexone for reversal of opioid urinary effects had a decrease in vomiting compared with those who received placebo. ${ }^{59} \mathrm{This}$ decrease in vomiting may have resulted from an action at the chemoreceptor trigger zone receptors or a modulation of afferent impulses from the enteric nervous system to the brain. ${ }^{72}$ However, another study ${ }^{58}$ did not show an effect on the prevention of postoperative nausea.

In conclusion, methylnaltrexone has been proven to be effective for treatment of opioid-induced constipation. Eventually it may prove useful for managing cases of opioid-induced nausea and vomiting, post-operative ileus, enteral feeding, pruritus, and urinary retention. However, on the latter indications data are very preliminary and require further evidence.

\section{Disclosures}

The authors declare no conflicts of interest.

\section{References}

1. Becker G, Galandi D, Blum HE. Peripherally acting opioid antagonists in the treatment of opiate-related constipation: a systematic review. J Pain Symptom Manage. 2007;34:547-565.

2. McNicol E, Horowicz-Mehler N, Fisk RA, et al. Management of opioid side effects in cancer-related and chronic noncancer pain: a systematic review. J Pain. 2003;4:231-256.

3. Schug SA, Zech D, Grond S, Jung H, Meuser T, Stobbe B. A long-term survey of morphine in cancer pain patients. J Pain Symptom Manage. 1992;7:259-266.

4. Becker G, Blum HE. Novel opioid antagonists for opioid-induced bowel dysfunction and postoperative ileus. Lancet. 2009;373:1198-1206.

5. Sepúlveda C, Marlin A, Yoshida T, Ullrich A. Palliative care: the World Health Organization's global perspective. J Pain Symptom Manage. 2002;24:91-96.

6. World Health Organization. Cancer Pain Relief. 2nd ed. Geneva, Switzerland: World Health Organization; 1996.

7. Christo PJ, Mazloomdoost D. Cancer pain and analgesia. Ann NY Acad Sci. 2008;1138:278-298.

8. Quigley C. The role of opioids in cancer pain. BMJ. 2005;331:825-829.

9. Panchal SJ, Muller-Schwefe P, Wurzelmann JI. Opioid-induced bowel dysfunction: prevalence, pathophysiology and burden. Int J Clin Pract. 2007;61:1181-1187.

10. Cherny N, Ripamonti C, Pereira J, et al. Strategies to manage the adverse effects of oral morphine: an evidence-based report. J Clin Oncol. 2001;19:2542-2554.

11. Camilleri M. Alvimopan, a selective peripherally acting mu-opioid antagonist. Neurogastroenterol Motil. 2005;17:157-165. 
12. Büchler MW, Seiler CM, Monson JR, et al. Clinical trial: alvimopan for the management of post-operative ileus after abdominal surgery: results of an international randomized, double-blind, multicentre, placebo-controlled clinical study. Aliment Pharmacol Ther. 2008;28:312-325.

13. Gomez-Flores R, Weber RJ. Immunomodulation of macrophage functions by opioids. Adv Exp Med Biol. 1998;437:13-19.

14. Gomez-Flores R, Rice KC, Zhang X, Weber RJ. Increased tumor necrosis factor-alpha and nitric oxide production by rat macrophages following in vitro stimulation and intravenous administration of the delta-opioid agonist SNC 80. Life Sci. 2001;68:2675-2684.

15. Kalff JC, Schraut WH, Billiar TR, Simmons RL, Bauer AJ. Role of inducible nitric oxide synthase in postoperative intestinal smooth muscle dysfunction in rodents. Gastroenterology. 2000;118:316-327.

16. Kowalski J. Augmenting effect of opioids on nitrite production by stimulated murine macrophages. Neuropeptides. 1998;32:287-291.

17. Yuan CS, Foss JF, O’Connor M, Toledano A, Roizen MF, Moss J. Methylnaltrexone prevents morphine-induced delay in oral-cecal transit time without affecting analgesia: a double-blind randomized placebocontrolled trial. Clin Pharmacol Ther. 1996;59:469-475.

18. Kurz A, Sessler DI. Opioid-induced bowel dysfunction: pathophysiology and potential new therapies. Drugs. 2003;63:649-671.

19. Sykes NP. The relationship between opioid use and laxative use in terminally ill cancer patients. Palliat Med. 1998;12:375-382.

20. Bernard SA, Bruera E. Drug interactions in palliative care. J Clin Oncol. 2000;18:1780-1799.

21. Ramesh PR, Kumar KS, Rajagopal MR, Balachandran P, Warrier PK. Managing morphine-induced constipation: a controlled comparison of an Ayurvedic formulation and senna. J Pain Symptom Manage. 1998;16:240-244.

22. Twycross RG, McNamara P, Schuijt C, Kamm MA, Jordan C. Sodium picosulfate in opioid-induced constipation: results of an open-label, prospective, dose-ranging study. Palliat Med. 2006;20:419-423.

23. Wirz S, Klaschik E. Management of constipation in palliative care patients undergoing opioid therapy: Is polyethylene glycol an option? Am J Hosp Palliat Care. 2005;22:375-381.

24. Sykes NP. An investigation of the ability of oral naloxone to correct opioid-related constipation in patients with advanced cancer. Palliat Med. 1996;10:135-144.

25. Daeninck PJ, Bruera E. Reduction in constipation and laxative requirements following opioid rotation to methadone: a report of four cases J Pain Symptom Manage. 1999;18:303-309.

26. Mazumdar A, Mishra S, Bhatnagar S, Gupta D. Intravenous morphine can avoid distressing constipation associated with oral morphine: A retrospective analysis of our experience in 11 patients in the palliative care in-patient unit. Am J Hosp Palliat Care. 2008;25: 282-284.

27. Donner B, Zenz M, Tryba M, Strumpf M. Direct conversion from oral morphine to transdermal fentanyl: a multicenter study in patients with cancer pain. Pain. 1996;64:527-534.

28. Ahmedzai S, Brooks D. Transdermal fentanyl versus sustained-release oral morphine in cancer pain: preference, efficacy, and quality of life. The TTS-Fentanyl Comparative Trial Group. J Pain Symptom Manage. 1997;13:254-261.

29. Payne R, Mathias SD, Pasta DJ, Wanke LA, Williams R, Mahmoud R. Quality of life and cancer pain: satisfaction and side effects with transdermal fentanyl versus oral morphine. J Clin Oncol. 1998;16: 1588-1593.

30. Radbruch L, Sabatowski R, Loick G, et al. Constipation and the use of laxatives: a comparison between transdermal fentanyl and oral morphine. Palliat Med. 2000;14:111-119.

31. Allan L, Hays H, Jensen NH, et al. Randomised crossover trial of transdermal fentanyl and sustained release oral morphine for treating chronic non-cancer. BMJ. 2001;322:1154-1160.

32. Pappagallo M. Incidence, prevalence, and management of opioid bowel dysfunction. Am J Surg. 2001;182:11S-18S

33. Wirz S. Opioid-induzierte Obstipation. Bremen, Germany: UNI-MED; 2009.
34. Gattuso JM, Kamm MA. Adverse effects of drugs used in the management of constipation and diarrhoea. Drug Saf. 1994;10: 47-65.

35. Müller-Lissner SA, Kamm MA, Scarpignato C, Wald A. Myths and misconceptions about chronic constipation. Am J Gastroenterol. 2005; 100:232-242.

36. Dipalma JA, Cleveland MV, McGowan J, Herrera JL. A randomized, multicenter, placebo-controlled trial of polyethylene glycol laxative for chronic treatment of chronic constipation. Am J Gastroenterol. 2007;102:1436-1441.

37. Jones MP, Talley NJ, Nuyts G, Dubois D. Lack of objective evidence of efficacy of laxatives in chronic constipation. Dig Dis Sci. 2002;47: 2222-2230.

38. Miles CL, Fellowes D, Goodman ML, Wilkinson S. Laxatives for the management of constipation in palliative care patients. Cochrane Database Syst Rev. 2006:CD003448.

39. Abou-madi MN, Chin SP, Yaboub JM, Keszler H. Effects of naloxone on postoperative analgesia. Anesth Analg (Paris). 1976;33: 757-762.

40. Gairola RL, Gupta PK, Pandley K. Antagonists of morphine-induced respiratory depression. A study in postoperative patients. Anaesthesia. 1980;35:17-21.

41. Lehmann KA, Reichling U, Wirtz R. Influence of naloxone on the postoperative analgesic and respiratory effects of buprenorphine. Eur J Clin Pharmacol. 1988;34:343-352.

42. Choi YS, Billings JA. Opioid antagonists: a review of their role in palliative care, focusing on use in opioid-related constipation. J Pain Symptom Manage. 2002;24:71-90.

43. Moss J, Rosow CE. Development of Peripheral Opioid Antagonists: New Insights Into Opioid Effects. Mayo Clin Proc. 2008;83: 1116-1130.

44. Yuan CS, Foss JF, Osinski J, Toledano A, Roizen MF, Moss J. The safety and efficacy of oral methylnaltrexone in preventing morphineinduced delay in oral-cecal transit time. Clin Pharmacol Ther. 1997;61: $467-475$.

45. Murphy DB, Sutton JA, Prescott LF, Murphy MB. Opioid-induced delay in gastric emptying: a peripheral mechanism in humans. Anesthesiology. 1997;87:765-770.

46. Foss JF, O’Connor MF, Yuan CS, Murphy M, Moss J, Roizen MF. Safety and tolerance of methylnaltrexone in healthy humans: a randomized, placebo-controlled, intravenous, ascending-dose, pharmacokinetic study. J Clin Pharmacol. 1997;37:25-30.

47. Yuan CS, Foss JF, O’Connor M, Osinski J, Roizen MF, Moss J. Effects of intravenous methylnaltrexone on opioid-induced gut motility and transit time changes in subjects receiving chronic methadone therapy: a pilot study. Pain. 1999;83:631-635.

48. Yuan CS, Foss JF, O'Connor M, et al. Effects of enteric-coated methylnaltrexone in preventing opioid-induced delay in oral-cecal transit time. Clin Pharmacol Ther. 2000;67:398-404.

49. Yuan CS, Wei G, Foss JF, O’Connor M, Karrison T, Osinski J. Effects of subcutaneous methylnaltrexone on morphine-induced peripherally mediated side effects: a double-blind randomized placebo-controlled trial. J Pharmacol Exp Ther. 2002;300:118-123.

50. Yuan CS, Doshan H, Charney MR, et al. Tolerability, gut effects, and pharmacokinetics of methylnaltrexone following repeated intravenous administration in humans. J Clin Pharmacol. 2005;45:538-546.

51. Yuan CS, Foss JF, O'Connor M, et al. Methylnaltrexone for reversal of constipation due to chronic methadone use: a randomized controlled trial. JAMA. 2000b; 283:367-372.

52. Portenoy RK, Thomas J, Moehl Boatwright ML, et al. Subcutaneous methylnaltrexone for the treatment of opioid-induced constipation in patients with advanced illness: a double-blind, randomized, parallel group, dose-ranging study. J Pain Symptom Manage. 2008;35: 458-468.

53. Thomas J, Karver S, Cooney GA, et al. Methylnaltrexone for opioid-induced constipation in advanced illness. $N$ Engl J Med. 2008;358:2332-2343. 
54. Slatkin N, Thomas J, Lipman AG, et al. Methylnaltrexone for treatment of opioid-induced constipation in advanced illness patients. J Support Oncol. 2009;7:39-46.

55. Yuan CS, Foss JF. Oral methylnaltrexone for opioid-induced constipation. JAMA. 2000;284:1383-1384.

56. Karver SB, Slatkin NE, Thomas J, Israel RJ. Methylnaltrexone treatment of opioid-induced constipation in cancer patients. ASCO Meeting Abstracts. 2007;25:9081.

57. Viscusi ER, Rathmell JP, Fichera A, et al. Methylnaltrexone bromide administered postoperatively to patients following segmental colectomy may accelerate bowel recovery and hospital discharge without affecting opioid analgesia. Am Soc Clin Oncol. 2007;43:A271.

58. Moerman I, Franck P, Camu F. Evaluation of methylnaltrexone for the reduction of postoperative vomiting and nausea incidences. Acta Anaesthesiol Belg. 1995;46:127-132.

59. Rosow CE, Gomery P, Chen TY, Stefanovich P, Stambler N, Israel R. Reversal of opioid-induced bladder dysfunction by intravenous naloxone and methylnaltrexone. Clin Pharmacol Ther. 2007;82:48-53.

60. Yuan CS, Foss JF, O’Connor M, Roizen MF, Moss J. Effects of low-dose morphine on gastric emptying in healthy volunteers. J Clin Pharmacol. 1998b;38:1017-1020.

61. Yuan CS, Foss JF, O’Connor M, Osinski J, Roizen MF, Moss J. Efficacy of orally administered methylnaltrexone in decreasing subjective effects after intravenous morphine. Drug Alcohol Depend. 1998a;52: 161-165.

62. Handal KA, Schauben JL, Salamone FR. Naloxone. Ann Emerg Med. $1983 ; 12: 438-445$

63. Wyeth Pharmaceuticals I. Relistor [package insert]. Philadelphia, PA:Wyeth pharmaceuticals; 2008.
64. Holzer P. Treatment of opioid-induced gut dysfunction. Expert Opin Investig Drugs. 2007;16:181-194.

65. Amin HM, Sopchak AM, Foss JF, Esposito BF, Roizen MF, Camporesi EM. Efficacy of methylnaltrexone versus naloxone for reversal of morphine-induced depression of hypoxic ventilatory response. Anesth Analg. 1994;78:701-705.

66. Yuan CS, Israel RJ. Methylnaltrexone, a novel peripheral opioid receptor antagonist for the treatment of opioid side effects. Expert Opin Investig Drugs. 2006;15:541-552.

67. DeHaven-Hudkins DL, DeHaven RN, Little PJ, Techner LM. The involvement of the mu-opioid receptor in gastrointestinal pathophysiology: therapeutic opportunities for antagonism at this receptor. Pharmacol Ther. 2008;117:162-187.

68. Reichle FM, Conzen PF. Methylnaltrexone, a new peripheral mu-receptor antagonist for the prevention and treatment of opioidinduced extracerebral side effects. Curr Opin Investig Drugs. 2008;9: 90-100.

69. Coremans G. Prucalopride: the evidence for its use in the treatment of chronic constipation. Core Evidence. 2009;3:45-54.

70. McNicol ED, Boyce D, Schumann R, Carr DB. Mu-opioid antagonists for opioid-induced bowel dysfunction. Cochrane Database Syst Rev. 2008:CD006332.

71. Woo M, O’Connor M, Yuan CS, Moss J. Reversal of opioid-induced gastric dysfunction in a critically ill burn patient after methylnaltrexone. Anesth Analg. 2008;107:1965-1967.

72. Yuan CS, Foss JF. Gastric effects of methylnaltrexone on mu, kappa, and delta opioid agonists induced brainstem unitary responses. Neuropharmacology. 1999;38:425-432.
Core Evidence

\section{Publish your work in this journal}

Core Evidence is an international, peer-reviewed open-access journal evaluating the evidence underlying the potential place in therapy of drugs throughout their development lifecycle from preclinical to postlaunch. The focus of each review is to evaluate the case for a new drug or class in outcome terms in specific indications and patient

\section{Dovepress}

groups. The manuscript management system is completely online and includes a very quick and fair peer-review system, which is all easy to use. Visit http://www.dovepress.com/testimonials.php to read real quotes from published authors. 